\title{
Expression studies on four members of the pMGA multigene family in Mycoplasma gallisepticum $\mathbf{S 6}$
}

\author{
Michelle D. Glew, Philip F. Markham, Glenn F. Browning and \\ Ian D. Walker
}

Department of Veterinary Science, The University of Melbourne, Parkville, Australia 3052

\author{
Author for correspondence: Ian D. Walker. Tel: +613344 7352/7355. Fax: +6133447374. \\ e-mail: Ian_Walker@muwayf.unimelb.edu.au
}

\begin{abstract}
A large family of related genes known as pMGA exists in the avian pathogen Mycoplasma gallisepticum but only a single member of this family was previously found to be expressed in one strain of this bacterium. In this work two unrelated strains of $M$. gallisepticum were also shown by amino-terminal sequencing to express a unique pMGA polypeptide in both cases. To investigate pMGA gene selection in $M$. gallisepticum, mRNA expression was analysed in $M$. gallisepticum strain $\mathbf{S 6}$ using reverse transcription-PCR (RT-PCR) and Northern blot techniques with probes for several members of the pMGA multigene family. It was shown that the PMGA message is $2.2 \mathrm{~kb}$ in size and is monocistronic. RT-PCR detected four different pMGA mRNA molecules but their relative yields were significantly affected by magnesium concentration. By quantitative Northern analysis, the relative abundances of the four PMGA mRNAs in M. gallisepticum S6 total RNA was determined: the pMGA1.1 mRNA predominated [1.88 $\mathrm{ng}$ ( $\mu \mathrm{g}$ total RNA) ${ }^{-1}$ ] but at least three other pMGA genes were found to be transcribed but at much lower levels (20 to 40-fold lower). The PMGA1.1 mRNA is expressed at a level five times higher than the tuf gene, known to be one of the most abundantly expressed proteins in the prokaryotic cell. The start point of transcription for pMGA1.1 was determined and probable promoter assigned. From these data it appears likely that transcriptional control plays a major role in the selection of pMGA gene expression in the $M$. gallisepticum cell.
\end{abstract}

\section{Keywords: pMGA, Mycoplasma gallisepticum, gene expression, RT-PCR, messenger RNA,} multigene family

\section{INTRODUCTION}

Mycoplasma gallisepticum is a bacterial pathogen which causes chronic respiratory disease in chickens, turkeys and other species of birds (Jordan, 1979; Simecka et al., 1992). It expresses a major cell surface protein, pMGA, which is attached to the membrane via a lipid anchor and which has been implicated as an agglutinin that may mediate adhesion to host cells (Markham et al., 1992). Earlier reports from this laboratory have documented the expression of apparently unique pMGA variants in three

Abbreviation: RT-PCR, reverse transcription-PCR.

The GenBank accession number for the nucleotide sequence data reported in this paper is L42637. strains of M. gallisepticum (Markham et al., 1992) with no evidence of any strain expressing more than one variant. A large repertoire of genes encoding pMGA-like proteins exists within the $\mathrm{S} 6$ strain of $M$. gallisepticum and we have estimated that the repertoire contains about 50 genes accounting for about $10 \%$ of the genome (Markham et al., 1994). Some genes have coding potential for strikingly similar proteins (pMGA1.1 and pMGA1.2 are $97 \%$ identical; Markham et al., 1993, 1994), whereas other pairs exhibit much lower identity levels $(<40 \%)$. Previous sequence studies have revealed that many, and perhaps all, pMGA genes could encode mRNA molecules which are potentially translatable as judged by the location of appropriate translational start and stop codons and the absence of internal stop codons. In an earlier report we studied the sequences of the segments $5^{\prime}$ to the trans- 
lational start codons in an attempt to locate relevant transcriptional elements (Markham et al., 1994). The impetus for this latter study was the expectation that the $5^{\prime}$ segment of the gene known to be expressed in the S6 strain of $M$. gallisepticum (pMGA1.1) might exhibit some obvious differences compared to the corresponding regions of other non-expressed pMGA genes. Whereas two putative promoter sites were located at the $5^{\prime}$ end of pMGA1.1, similar or identical sites were found in all other pMGA gene $5^{\prime}$ regions examined; all such regions exhibited high sequence homology throughout the region between putative transcriptional and translational start signals (Markham et al., 1994). The pMGA genes of $M$. gallisepticum are arranged in tandem and in the same transcriptional orientation within several clusters throughout the genome (unpublished). The distance between the translational stop codon of one gene and the start codon of the adjacent gene is $400 \pm 50$ nucleotides (Markham et al., 1994). This work left unresolved the issue of how pMGA gene selection was accomplished in $M$. gallisepticum and indeed cast some doubt on the importance of transcriptional control in the gene selection process. We therefore decided to examine the nature of the pMGA transcripts in $M$. gallisepticum cells and document two major findings herein. Firstly, pMGA $m R N A$ is monocistronic and is synthesized from a single transcriptional start site. Secondly, whereas many pMGA genes are simultaneously transcribed within the S6 strain of $M$. gallisepticum the pMGA1.1 gene is expressed at a level 20 to 40 -fold higher than any other pMGA gene examined and is the only pMGA gene product to be detected.

\section{METHODS}

Bacterial strains, growth conditions and plasmids. $M$. gallisepticum strains S6, F, R, and Mycoplasma pullorum were grown to late exponential phase in modified Frey's medium (Frey et al., 1968) supplemented with $10 \%$ swine serum (Higgins \& Whithear, 1986). The material derived from $M$. gallisepticum S6 used in this work was obtained from a single ampoule (passage 313) which was thawed and passed through a $0.45 \mu \mathrm{m}$ filter (Sartorius). Appropriate dilutions were then plated on solid (agar) media to obtain discrete colonies and a single colony was selected for broth culture which was used as an inoculum to obtain cells for subsequent RNA and protein extractions. Plasmid pMCC4bHP is Bluescript SK - containing a $2 \cdot 2 \mathrm{~kb}$ HindIII-PstI DNA fragment, subcloned from pMCC4 (described by Markham et al., 1994). It contains the $5^{\prime}$ untranslated region and the first 65 bases of the coding sequence of the pMGA1.1 gene.

Amino-terminal protein sequencing. $M$. gallisepticum cells were washed twice in PBS (150 mM NaCl, $16 \mathrm{mM} \mathrm{Na}_{2} \mathrm{HPO}_{4}, 4 \mathrm{mM}$ $\mathrm{NaH}_{2} \mathrm{PO}_{4}, \mathrm{pH} 7 \cdot 2$ ). The cell pellet was resuspended in SDSPAGE sample buffer and constituent proteins separated on a $10 \%(\mathrm{w} / \mathrm{v})$ gel (Laemmli, 1970) followed by electrophoretic transfer onto an Immobilon-P PVDF membrane (Millipore) using CAPS buffer (Matsudaira, 1987) The membrane was stained with Coomassie blue, de-stained in $50 \%(\mathrm{v} / \mathrm{v})$ aqueous methanol and the pMGA protein band for each strain excised and sequenced as previously described (Markham et al., 1992). Guide strips from the PVDF membranes were immunostained using a rabbit polyclonal antiserum to purified pMGA from
M. gallisepticum strain S6 to unambiguously locate the corresponding Coomassie blue species before excision.

Northern blotting. Mycoplasma cells grown to late exponential phase, were immediately processed for RNA extraction (Chomczynski \& Sacchi, 1987). Briefly, $40 \mathrm{ml}$ cell suspension was spun at $20000 \mathrm{~g},\left(10 \mathrm{~min}, 4^{\circ} \mathrm{C}\right)$ and resuspended in $400 \mu \mathrm{l}$ PBS. The cells were homogenized in $10 \mathrm{ml}$ denaturing buffer (4 M guanidinium thiocyanate, $25 \mathrm{mM}$ sodium citrate, $\mathrm{pH} 7$; $0.1 \mathrm{M} \beta$-mercaptoethanol) with a $5-10 \mathrm{~s}$ polytton burst, then processed according to the method described by Chomczynski \& Sacchi (1987). RNA was fractionated by electrophoresis using a $1.2 \%$ agarose gel containing $0.22 \mathrm{M}$ formaldehyde (Sylvers \& Beresten, 1993) and transferred to Hybond-N membrane (Amersham). A PstI-BglII DNA fragment $(1.2 \mathrm{~kb})$ of the pMGA1.2 gene which has $98 \%$ identity to the corresponding segment of pMGA1.1 (Markham et al., 1993) was labelled to a specific activity of $>10^{9}$ c.p.m. $\mu \mathrm{g}^{-1}$ with $[\alpha-$ $\left.{ }^{32} \mathrm{P}\right] \mathrm{dATP}\left[\sim 3000 \mathrm{Ci} \mathrm{mmol}^{-1}\left(111 \mathrm{TBq} \mathrm{mmol}^{-1}\right)\right.$; Amersham] using a Random Primed DNA Labelling Kit (Boehringer Mannheim). The labelled probe was hybridized with the membrane in Church buffer (Church \& Gilbert, 1984) at $65^{\circ} \mathrm{C}$ overnight. Excess label was removed and the membrane stringently washed in $0.5 \times \mathrm{SSC}(1 \times \mathrm{SSC}$ is $0.15 \mathrm{M} \mathrm{NaCl}$, $0.015 \mathrm{M}$ sodium citrate, $\mathrm{pH} 7 \cdot 4), 0.5 \% \mathrm{SDS}$ at $65^{\circ} \mathrm{C}$ for $1 \mathrm{~h}$ and exposed to XAR film for $30 \mathrm{~min}$.

Design of oligonucleotides for reverse transcription-PCR (RTPCR). Three consensus primers were designed from regions of highest homology from an alignment between five already sequenced pMGA genes; 1.1 (GenBank accession number L28423), 1.2, 1.3, 1.4 and 1.5 (GenBank accession number L28424). These sequences were aligned using CLUSTAL $v$ (Higgins et al., 1992) as represented in Fig. 4. Ten noncomplementary additional nucleotides (which included the recognition site for EcoRI) were appended to the $5^{\prime}$ ends of both T22 and T23 primers. As a control for the RT-PCR system, three similarly positioned primers were designed based on the M. gallisepticum elongation factor $\mathrm{Tu}$ (TuF) gene sequence (GenBank accession number X16462; Loechel et al., 1989): TuF R'T primer (A25), 5' TACACCACGAAGTAAGATCCCA 3'; TuF PCR $5^{\prime}$ primer (G15), 5' TTCGATCGTAGTAAACCTCACG 3'; TuF PCR 3' primer (C26), 5' GACGATTTTGAG'T'TCGTATTC 3'. Expected PCR product sizes for each pMGA gene type were calculated to be $188 \mathrm{bp}$ (1.1), $185 \mathrm{bp}$ (1.2), $233 \mathrm{bp}$ (1.3), $242 \mathrm{bp}$ (1.4) and $230 \mathrm{bp}$ (1.5). The predicted size for the TuF PCR product was $211 \mathrm{bp}$.

Reverse transcription (RT) of RNA samples. Samples of RNA were prepared from $M$. gallisepticum cells as described for Northern blotting studies. Before synthesis of cDNA, RNA samples $(2 \mu \mathrm{g})$ were treated with $10 \mathrm{U}$ RNase-free DNase I (Boehringer Mannheim) in a total volume of $12 \mu \mathrm{l}$ containing $4 \mu \mathrm{l} 5 \times \mathrm{RT}$ buffer $(5 \times \mathrm{RT}$ is $250 \mathrm{mM}$ Tris/ $\mathrm{HCl}, \mathrm{pH} 8.3$, $375 \mathrm{mM} \mathrm{KCl}, 15 \mathrm{mM} \mathrm{MgCl}$, $50 \mathrm{mM} \mathrm{DTT})$. Digestion was conducted for $30 \mathrm{~min}$ at $37^{\circ} \mathrm{C}$ followed by $70^{\circ} \mathrm{C}$ for $10 \mathrm{~min}$ to heat-inactivate the DNase I enzyme. The reaction mixture was then placed on ice and $2 \mu \mathrm{l}$ of each primer, A23 $\left(0.2 \mathrm{mg} \mathrm{ml}^{-1}\right)$ and A25 $\left(0.05 \mathrm{mg} \mathrm{m}^{-1}\right)$, were added along with $2 \mu \mathrm{l} 0.1 \mathrm{M}$ DTT and $1 \mu \mathrm{l}$ of all four deoxyribonucleotide triphosphates (dNTPs) each at $10 \mathrm{mM}$. The reaction mixture was prewarmed to $37^{\circ} \mathrm{C}$ for $2 \mathrm{~min}$ and $400 \mathrm{U}$ Moloney-murine leukaemia virus RNase $\mathrm{H}^{-}$reverse transcriptase (M-MLV) from Promega was added and the reaction incubated at $37^{\circ} \mathrm{C}$ for $1 \mathrm{~h}$. The reaction was stopped by heating to $70^{\circ} \mathrm{C}$ for $10 \mathrm{~min}$. Water was added to a final volume of $100 \mu \mathrm{l}$ and $0.5 \%$ of the resultant cDNA sample used for PCR. For the RNase A-treated control experiment, the $\mathrm{R} T$ reaction was conducted as described above for cDNA 
synthesis except that RNase A (Pharmacia) was added to a final concentration of $10 \mu \mathrm{g} \mathrm{ml}^{-1}$ during DNase I treatment.

PCR. PCR amplifications were performed in a final volume of $50 \mu$ l. The buffer composition of each reaction was $10 \mathrm{mM} \mathrm{KCl}$, $10 \mathrm{mM}\left(\mathrm{NH}_{4}\right)_{2} \mathrm{SO}_{4}, 20 \mathrm{mM}$ Tris/ $\mathrm{HCl}, \mathrm{pH} 8.8,2 \mathrm{mM} \mathrm{MgSO}_{4}$, and $0.1 \%$ Triton X-100, $0.5 \mu$ of the cDNA template, $0.4 \mu \mathrm{M}$ of

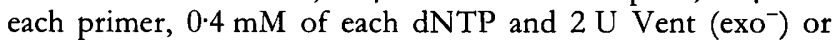
$0.5 \mathrm{U}$ Vent (exo ${ }^{+}$) DNA polymerase (New England Bio Labs). In certain reactions additional magnesium was added to a final concentration of $4 \mathrm{mM}$ as indicated in the text. The PCR amplification cycle $\left(94^{\circ} \mathrm{C}, 30 \mathrm{~s} ; 45^{\circ} \mathrm{C}, 45 \mathrm{~s} ; 72^{\circ} \mathrm{C}, 30 \mathrm{~s}\right)$ for exopolymerase, or $\left(94^{\circ} \mathrm{C}, 30 \mathrm{~s} ; 45^{\circ} \mathrm{C}, 20 \mathrm{~s} ; 72^{\circ} \mathrm{C}, 15 \mathrm{~s}\right)$ for exo ${ }^{+}$ polymerase was repeated 40 times. A $15 \mu$ sample from each PCR reaction was subjected to electrophoresis on a $2 \%$ agarose gel.

Cloning of PCR products and DNA sequencing. PCR products were purified by extraction with an equal volume of chloroform, precipitated with ethanol and then resuspended in water. Purified PCR DNA was ligated into the PGEM-T vector system (Promega) and the ligation product used to transform DH5 $\alpha$ cells (Sambrook et al., 1989) using a Bio-Rad electroporation unit. Samples of recombinant plasmid DNA were screened by digestion with appropriate restriction enzymes for the presence of insert. Double-stranded recombinant plasmid DNA was prepared (Del Sal et al., 1988) and sequenced using T7 DNA polymerase with deaza-G/A sequencing mixes (Pharmacia) and standard $\mathrm{pUC}$ forward and reverse primers.

Quantification of specific mRNA molecules. To measure the absolute amounts of specific mRNA molecules within total RNA, the following strategy was adopted. First, pure synthetic (PCR size) RNA molecules were obtained for use as titration standards by in vitro transcription of selected recombinant plasmids. In brief, the plasmids selected were linearized with Sall digestion and transcribed using T7 RNA polymerase and Riboprobe Core System kit reagents (Promega) to produce mRNA sense molecules. The DNA templates used to produce synthetic RNA of the gene types specified were as follows (see Fig. 5): clone 16 (pMGA1.1 gene), clone 7 (pMGA1.2 gene), clone 5 (pMGA1.4 gene); clone 3 (pMGA1.8-like gene called pMGA'1.8') and an appropriate segment of the TuF gene (see Fig. 3, lane 6) also cloned into pGEM-T. Each synthetic RNA sample was treated with DNase I, shown by electrophoresis to contain a species of the correct size and quantified spectrophotometrically $\left(A_{\mathbf{2 6 0}}\right)$. Serial dilutions of these synthetic RNA samples were dotted onto Hybond-N membrane strips to enable the relationship between radioactive signal and absolute amount to be estimated. Known amounts of total RNA samples from both $M$. gallisepticum and $M$. pullorum cells were fractionated using formaldehyde-agarose gels and then blotted onto $\mathrm{Hy}$ bond-N membranes. Blots of both synthetic RNA samples and separated Mycoplasma total RNA were then hybridized to labelled PCR probes for pMGA1.1, pMGA1.2, pMGA1.4, pMGA'1.8' and TuF sequences. In all cases hybridized membranes were washed in $0.5 \times \mathrm{SSC}, 0.5 \%$ SDS for $1.5 \mathrm{~h}$ at $65^{\circ} \mathrm{C}$ (pMGA1.1, pMGA1.2 and TuF) or $68^{\circ} \mathrm{C}$ (pMGA1.4 and pMGA'1.8') and subjected to autoradiography using XAR film with an intensifying screen (Kodak) at $-70^{\circ} \mathrm{C}$ for $22 \mathrm{~h}$. Quantification of the intensities of the radioactive signals was performed using a Molecular Dynamics 400 series phosphorimager and volume integration. For each probe the slope of the dot intensities of the dilution series of the corresponding synthetic RNA was calculated by linear regression. Each band intensity for the Northern blots was similarly determined and the amount of mRNA present was calculated from the standard curve, adjusted for size difference between full length mRNA and synthetic RNA and expressed as ng mRNA ( $\mu \mathrm{g}$ total RNA) ${ }^{-1}$.

Primer extension analysis. A 23-mer oligonucleotide, $\left(5^{\prime}\right.$ GCCAATAACT'TACGTTAAACACG 3') indicated in Fig. 7(b), complementary to the $5^{\prime}$ region of pMGA1.1 was endlabelled with $\left[\gamma_{-}{ }^{33} \mathrm{P}\right]$ ATP with $70 \%$ incorporation. Labelled primer $(10 \mathrm{ng})$ was hybridized at $67^{\circ} \mathrm{C}$ with $10 \mu \mathrm{g} M$. gallisepticum S6 total RNA (prepared as described above) and slowly cooled to $42^{\circ} \mathrm{C}$. Reverse transcription was carried out using avian myeloblastosis virus reverse transcriptase (Promega) with $1 \mathrm{mM}$ final concentration of dNTPs (Sambrook et al., 1989). Approximately $10^{6}$ c.p.m. of $\left[\gamma^{-32} \mathrm{P}\right]$ ATP-labelled extension primer and pMCC4bHP was used to produce the pMGA1.1 dideoxynucleotide sequencing ladder standard using $\mathrm{T} 7$ polymerase and short sequencing mixes (Pharmacia).

\section{RESULTS}

\section{Single unique proteins are expressed in three M. gallisepticum strains}

To confirm our earlier suggestion that the molecular differences between the pMGA molecules of three different $M$. gallisepticum clones were due to genetic rather than post-synthetic factors (Markham et al., 1992), the amino-terminal sequences of homologous pMGA proteins from $M$. gallisepticum strains $\mathrm{R}$ and $\mathrm{F}$ were elucidated. These sequences along with the corresponding sequence of pMGA from $M$. gallisepticum S6 strain and selected sequences predicted from several pMGA genes are presented in Fig. 1. These data leave no doubt that the differences between the pMGA variants expressed in different $M$. gallisepticum strains are indeed genetically determined.

\section{Analysis of pMGA mRNA}

Northern blot analysis of $M$. gallisepticum S6 total RNA, using a PstI-BglII fragment of the pMGA1.2 gene (previously shown to cross-hybridize with many, perhaps all pMGA genes; Markham et al., 1993, 1994) as a probe,

\subsection{CTTPTPSPAPNPNPPSNGGMNGG}



$$
\begin{aligned}
& \text { F ?...V.N.T........ } \\
& \text { R } \quad \text {.....T......... } \\
& 1.2 \ldots \ldots \text {. . . .......... }
\end{aligned}
$$

Fig. 1. Amino-terminal sequences of homologous pMGA proteins from three different $M$. gallisepticum strains. Sequences are aligned to maximize similarity between the corresponding segments of S6, R and F strain pMGA proteins and the sequences predicted by pMGA genes 1.1 and 1.2 from strain S6. Dots indicate identities to the pMGA1.1 sequence, dashes indicate gaps introduced to maximize alignment. No assignment of residue 1 was possible in either $F$ or $R$ strain pMGA sequences. 


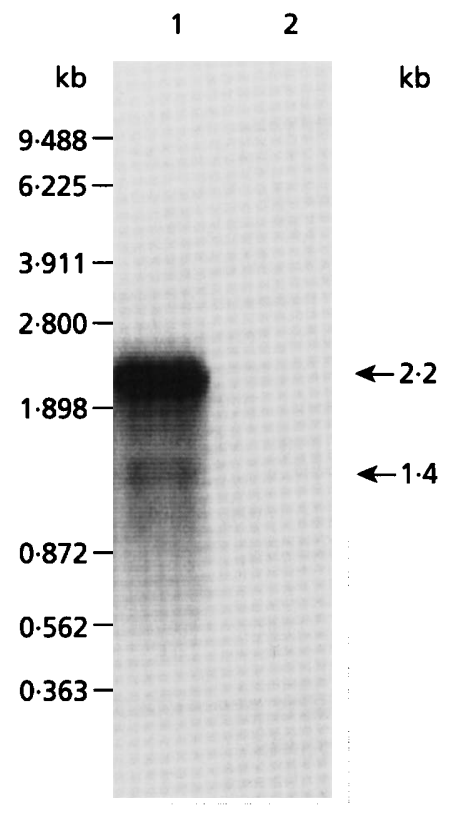

Fig. 2. Northern blot of Mycoplasma total RNA. Mycoplasma RNA was electrophoretically separated using a $1.2 \%$ agaroseformaldehyde denaturing gel and transferred to a Hybond $\mathrm{N}$ membrane which was subsequently probed with a ${ }^{32} \mathrm{P}$-labelled $1.2 \mathrm{~kb}$, Pstl-Bg/ll fragment of the pMGA1.2 gene. The membrane was autoradiographed on XAR film. RNA molecular mass standards were from Promega. Lanes: $1,2 \mu \mathrm{g} M$. gallisepticum S6 RNA; 2, $2 \mu \mathrm{g} M$. pullorum RNA.

detected one major and several minor bands (Fig. 2). The most abundant mRNA species was $2.2 \mathrm{~kb}$ in size. Smaller species were considerably less abundant and even that of $1.4 \mathrm{~kb}$ would not be large enough to encode an entire pMGA molecule. This and other fainter bands may represent breakdown intermediates of the pMGA mRNA. Failure of the pMGA probe to detect any species in an equivalent amount of $M$. pullorum RNA showed that the probe did not bind to Mycoplasma 23S rRNA which has a mobility similar (but not identical) to the RNA species detected.

\section{RT-PCR}

To further analyse pMGA gene expression in $M$. gallisepticum cells, it was decided to analyse the sequence of individual mRNA molecules by cloning and then sequencing their cDNA copies. The RNA sample used to synthesize cDNA was obtained from a clone of $M$. gallisepticum strain S6. This was done to reduce the likelihood that the starting inoculum contained significant proportions of cells that may be expressing an alternative form of pMGA. To establish the suitability of the cDNA sample as a template for PCR of pMGA transcripts, preliminary experiments were conducted using oligonucleotide primers based on the known sequence of the TuF mRNA of M. gallisepticum (Loechel et al., 1989) which derives from a single copy gene and is abundantly expressed, at least in Escherichia coli (Pedersen et al., 1978). Using the RT and PCR primers described in Methods, the predicted TuF PCR product of $211 \mathrm{bp}$ was observed from $M$. gallisepticum S6 cDNA (Fig. 3, lane 6), indicating that the TuF mRNA was intact and that the RT-PCR system was working. The pre-treatment by DNase I of RNA samples ensured the removal of any contaminating DNA (Fig. 3, lane 7). The absence of a PCR product from cDNA derived from RNA additionally pre-treated with RNase A before the RT reaction (Fig. 3, lane 8) further establishes that the DNA species amplified by PCR is specifically derived from reverse-transcribed RNA and not from contaminating $M$. gallisepticum genomic DNA. The addition of $\mathrm{Mg}^{2+}$ to $4 \mathrm{mM}$ did not substantially affect the TuF reaction product (Fig. 3, lane 12) nor did pretreatment of template cDNA by RNase A prior to the PCR. This latter observation rules out any possibility that

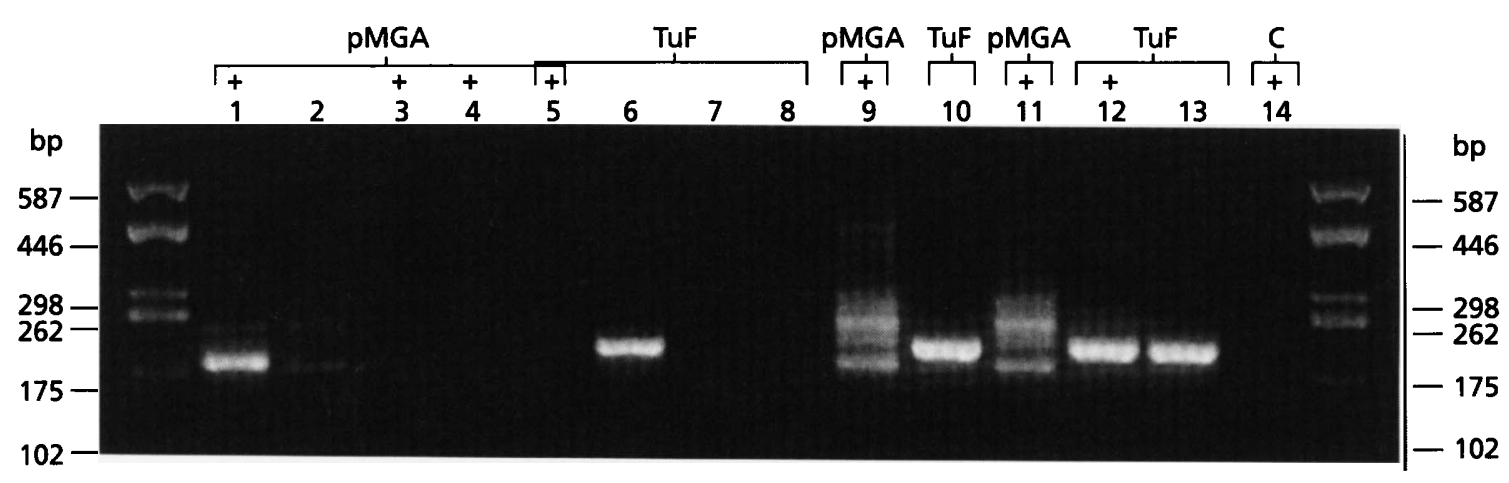

Fig. 3. PCR products from reverse-transcribed $M$. gallisepticum S6 RNA template. Details of PCR conditions are described in Methods. Primer sets used in the PCR reactions are shown above lane numbers (PMGA, T22 and T23; TUF, G15 and C26). The ' + ' symbol above lane numbers indicates that $4 \mathrm{mM}$ (rather than $2 \mathrm{mM}$ ) final concentration of magnesium was used. Templates used in each PCR sample were as follows: lanes 1, 2 and 6, reverse-transcribed RNA; lanes 4 and 8, RNase A-treated and reverse-transcribed RNA; lanes 3 and 7, DNase 1-treated RNA only (no RT enzyme); lane 5, M-MLV RT enzyme only (no RNA template); lanes 9 and 10, same as for lane 4 but with 5 ng M. gallisepticum S6 DNA; lanes 11,12 and 13, M. gallisepticum S6 DNA only; lane 14, PCR control with both pMGA and TuF PCR primers and no template added. 


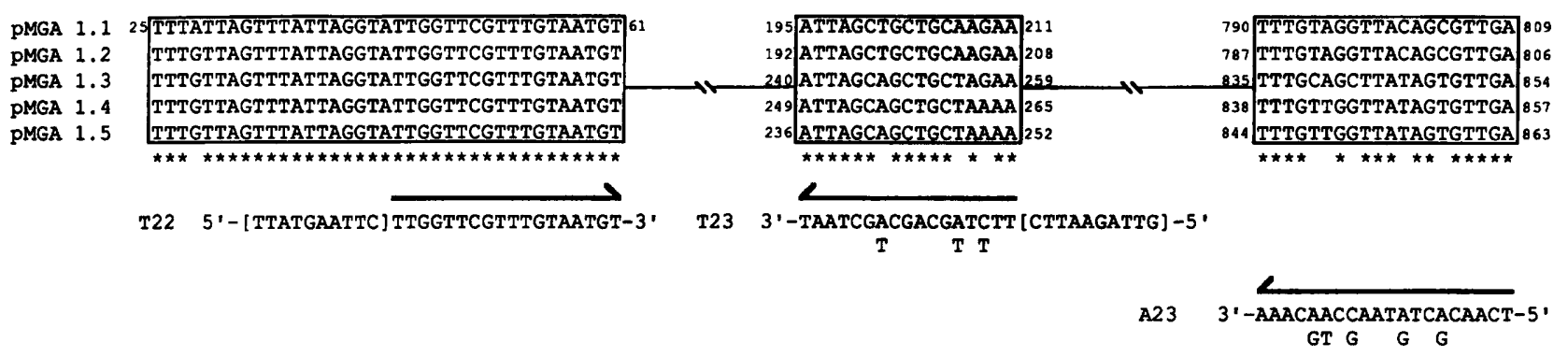

Fig. 4. PMGA oligonucleotides used for RT-PCR. Five PMGA genes, 1.1-1.5, (Markham et al., 1994) were aligned and regions of high homology between all five genes were selected for oligonucleotide design and are shown boxed. Sequences between boxed regions are represented by interrupted lines. Nucleotide positions are numbered relative to the first base of the GUG start codon for each gene. An asterisk directly below the alignment shows nucleotides that are conserved in all five pMGA gene sequences. Oligonucleotide sequences corresponding to the primers of this work are shown below the alignment and arrows indicate their polarities. Nucleotides within brackets for primers T23 and T22 indicate additional non-complementary nucleotides which contain EcoRI cleavage sites.

a negative PCR result was due to inhibitory substances derived from RNase A treatment.

Oligonucleotides to conduct amplification of pMGA mRNA molecules are depicted in Fig. 4. The sequences selected were identical (or complementary) to segments which were highly conserved between all known pMGA genes and were likely to facilitate the amplification and therefore the detection of many, perhaps all homologous sequences if indeed these genes were transcribed. Electrophoretic analysis of the products of RT-PCR reactions using the pMGA primer set shown in Fig. 4 revealed two bands approximately $190 \mathrm{bp}$ and $240 \mathrm{bp}$ in size (Fig. 3, lanes 1 and 2). The $190 \mathrm{bp}$ product predominated when PCR was conducted with a final $\mathrm{Mg}^{2+}$ concentration of $4 \mathrm{mM}$ (Fig. 3, lane 1) but use of a lower $\mathrm{Mg}^{2+}$ concentration of $2 \mathrm{mM}$ resulted in an increase in the relative abundance of the upper (240 bp) band (Fig. 3, lane 2). The lower band in Fig. 3 , lane 2 (using $2 \mathrm{mM} \mathrm{Mg}^{2+}$ ), although approximately equimolar with the upper band, was appreciably lower in yield (by approximately 20 -fold) than when $4 \mathrm{mM} \mathrm{Mg}^{2+}$ was used. The 190 bp species would be expected from PCR amplification of either PMGA1.1 or 1.2 mRNA molecules, whereas the $240 \mathrm{bp}$ species is consistent with the pMGA1.3, 1.4, 1.5 and closely related genes. As with TuF, control experiments were performed. The omission of reverse transcriptase from the reaction mixture depicted in Fig. 3, lane 3, or pretreatment of RNA with RNase A before the reverse transcription reaction (Fig. 3, lane 4) resulted in the absence of any significant PCR product. Moreover, a greater number of PCR product sizes were obtained using $M$. gallisepticum genomic DNA as template (Fig. 3, lane 11), than with cDNA as template (Fig. 3, lanes 1 and 2).

\section{Sequence analysis of pMGA mRNA molecules obtained by RT-PCR}

The sequences of PCR products obtained from three separate PCR amplification reactions are depicted in Fig. 5. All cloned PCR sequences are grouped under the corresponding segment of one or other known pMGA gene. Those sequences prefixed by $\mathrm{E}$ were obtained using a polymerase enzyme with proofreading capacity $\left(\mathrm{exo}^{+}\right)$, those without the prefix were obtained using a polymerase without proofreading capacity $\left(\mathrm{exo}^{-}\right)$. The DNA products of the latter category were obtained from PCR amplifications containing $4 \mathrm{mM} \mathrm{Mg}^{2+}$ (Fig. 3, lane 1) or $2 \mathrm{mM}$ $\mathrm{Mg}^{2+}$ (Fig. 3, lane 2). Control experiments were carried out in which seven TuF PCR products (Fig. 3, lane 6) were cloned, sequenced and found to be identical (data not shown). The amplification reactions using pMGA primers produced a range of products most of which resembled pMGA1.1 or pMGA1.2 sequences. A sequence identical to part of the pMGA1.4 gene and several sequences which bore limited homology to the pMGA1.8 gene were also amplified. Differences between 'authentic' pMGA sequences and their PCR-derived counterparts were much more frequent in experiments where the polymerase used lacked exonuclease proofreading capacity. Use of $2 \mathrm{mM} \mathrm{Mg}^{2+}$ seemed to lower the yield of pMGA1.1/1.2 PCR products relative to the pMGA1.4/‘'1.8' PCR counterparts.

The results shown in Fig. 5 extablish that at least four different pMGA genes are expressed in the cell population used and it was observed that the exact choice of PCR conditions influenced the relative abundance of these pMGA species by PCR (see Discussion).

Many of the nucleotide differences between the pMGA1.1 sequence and the PCR products which most resemble it (Fig. 5) would cause amino acid sequence alterations which were not detected by direct protein sequencing of the pMGA1.1 protein: these changes are almost certainly errors introduced by the low fidelity of the $\mathrm{exo}^{-}$polymerase used.

\section{Quantification of individual pMGA mRNA molecules in $M$. gallisepticum}

The PCR experiments of the previous section did not allow quantification of the individual pMGA mRNA molecules. It was therefore decided to quantify several 

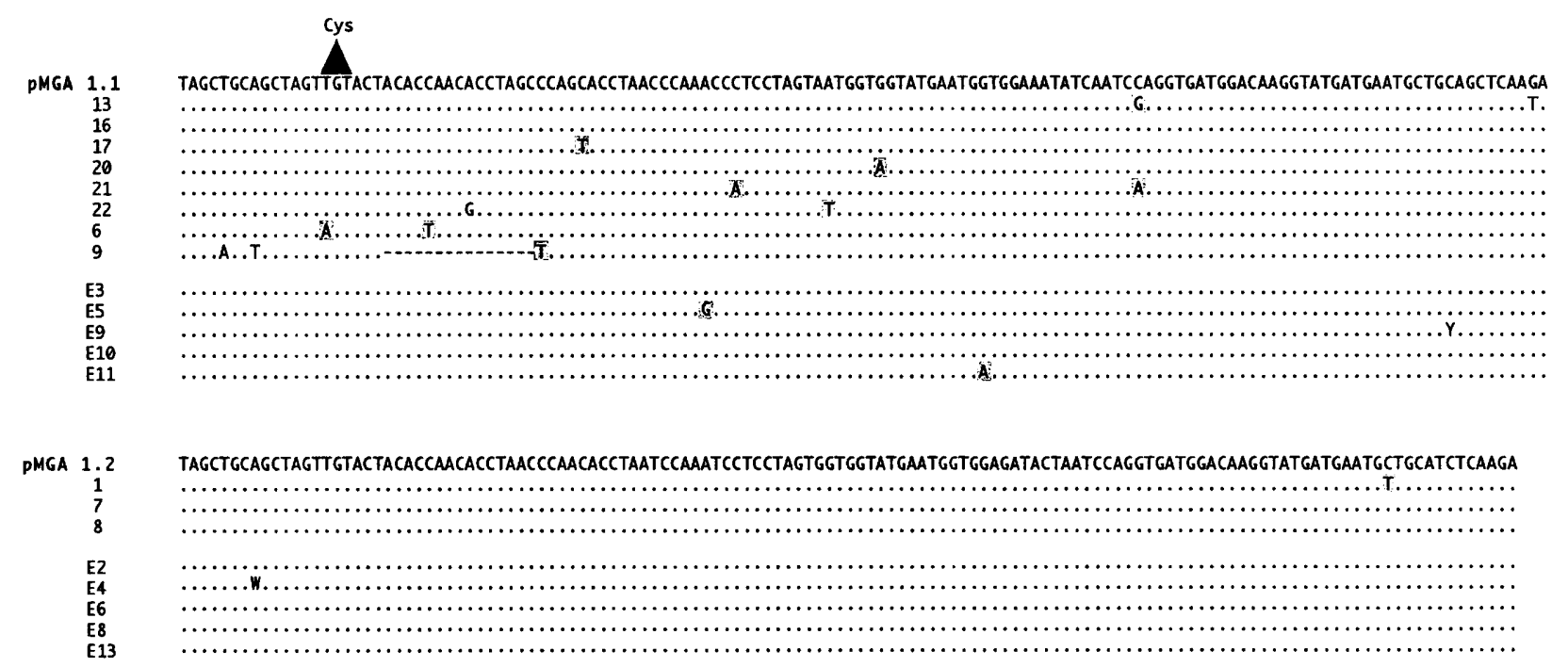

PMGA $\frac{1.4}{5}$ TGGCAGCAGCTAGTTGTACTACACCGGTCAACCCAACTCCAAAGCCAAAGCCAAACCCTGAACCAAAGCCAAACCCTGCACCAAAACCAGATCC

PMGA 1.4 AATGCCAAATCCTGGTGGGGTATGATGGGGGTATGAATGGGGAAATACTAATCCAGGGAATGGGGGGGAACGGACAATGCTGCTCAGCA

PMGA 1.8 TGGC--AGCTGCAAGCTGTACTACACCGGTCAACCCAACACCTAACCCTGAACCAAAGCCAACTCCAAACCCTGAACCA-AaGCCAAAT-CCTGGTGG---

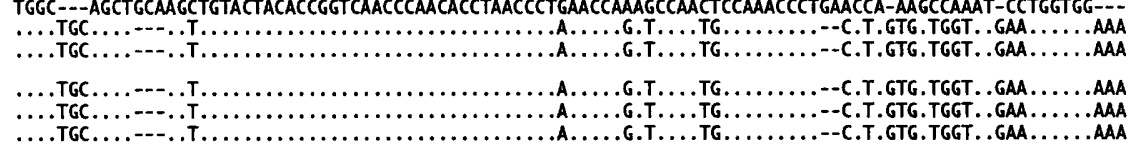

PMGA 1.8 --TGGTGACA-TGAATCCAAATCATCCTAGGGGGGT---ATGAATGGCGGAGATACTAATCCAGGTGATGGACAAGGCATGATGAATGCTACTAACCAGGA

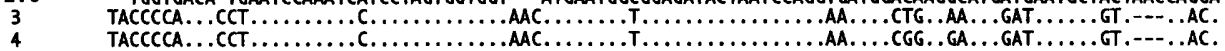

E1

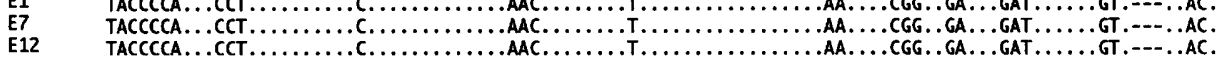

Fig. 5. Sequence alignments of cloned pMGA PCR products. Nucleotide sequences of pMGA PCR inserts are aligned and grouped with known pMGA genes (1.1, 1.2, 1.4 and pMGA '1.8'). Nucleotides that cause an amino acid change are highlighted. Only the sequence between (but not including) the pMGA primers (T22/T23) is shown for each clone. $Y=C$ or $\mathrm{T} ; \mathrm{W}=\mathrm{A}$ or $\mathrm{T}$.

pMGA gene transcripts using Northern blot analysis. Firstly, synthetic RNA standards were transcribed in vitro using T7 RNA polymerase and pGEM plasmid templates containing PCR inserts corresponding to the PMGA1.1, pMGA1.2, pMGA1.4, pMGA'1.8' or TuF gene. Templates were selected so that sense RNA molecules were obtained which encompassed sequences between the pMGA PCR primers T22 and T23 (Fig. 4). Gel analysis of all synthetic RNA molecules confirmed the success of all RNA syntheses as well as the molecular sizes anticipated from their respective templates (not shown). A dilution series of known amounts of all five RNA species attached to Hybond-N strips was constructed and hybridized in separate experiments to cognate probes for all four pMGA genes and TuF (Fig. 6a). Clearly, under the hybridization and washing conditions selected, all probes used were essentially gene-specific, although slight cross-hybridization occurred between pMGA1.1 and pMGA1.2 (Fig. 6a). The Northern transfer data (Fig. 6b) established the presence of transcripts derived from pMGA genes 1.1, $1.2,1.4$ and ' 1.8 ' and confirmed the results of PCR analysis in Fig. 5. Quantitative estimations of absolute mRNA amounts based upon comparison of autoradiographic intensities of specific mRNA bands with known amounts of synthetic RNA are presented in Table 1 . Clearly, the amount of pMGA1.1 mRNA present [1.88 ng $(\mu \mathrm{g} \text { total RNA })^{-1}$ ] exceeds the amounts of pMGA1.2, pMGA1.4 or pMGA' 1.8 ' by 20 to 40 -fold. The level of pMGA1.1 mRNA is about fivefold more abundant than TuF (about $0.2 \%$ and $0.04 \%$ of total RNA, respectively). If it is assumed that mRNA comprises $2 \%$ of total RNA in $M$. gallisepticum cells, then pMGA mRNA alone would account for about $10 \%$ of total mRNA. This seems inordinately high and certainly exceeds the relative abundance of the pMGA proteins (say $1-2 \%$ of total protein). Perhaps Mycoplasma cells contain more mRNA relative to rRNA and tRNA than other cells. No data or literature on this point are available to date. 
(a)



(b)

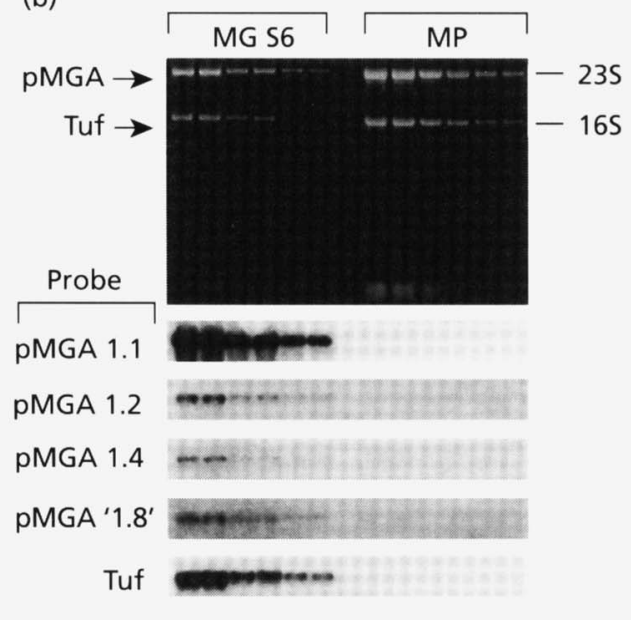

Fig. 6. Detection of specific pMGA mRNA molecules. (a) The indicated pMGA synthetic RNA molecules (0.5 ng) were dotted onto nylon membrane and individual strips were hybridized with the labelled probe indicated at the top of each strip, under the same hybridization and washing conditions as in (b). (b) Northern transfer analysis of $M$. gallisepticum (MG) and $M$. pullorum (MP) RNA. The ethidium-bromide-stained gel is depicted above and the positions of the 235 and 165 ribosomal RNA molecules and the relative positions of the pMGA and TuF mRNA molecules are shown. Autoradiogram strips of replicate Northern blots are depicted below with the labelled probe used to detect mRNA indicated to the left of each strip. Twofold serial dilutions of both MG and MP RNA samples were loaded in duplicate in the following order: $2 \mu \mathrm{g}, 1 \mu \mathrm{g}, 0.5 \mu \mathrm{g}$.

Table 1. Estimation of pMGA and Tuf mRNA levels in M. gallisepticum strain $\mathrm{S6}$

\begin{tabular}{|cc|}
\hline mRNA & mRNA (ng)/total RNA ( $\mu$ g) \\
\hline 1.1 & $1 \cdot 88$ \\
1.2 & $0 \cdot 11$ \\
1.4 & $0 \cdot 055$ \\
$' 1.8$ ' & $0 \cdot 050$ \\
Tuf & $0 \cdot 40$ \\
\hline
\end{tabular}

\section{The PMGA1.1 transcriptional start}

Primer extension analysis (Fig. 7) was employed to define the first nucleotide of the pMGA mRNA expressed in $\mathrm{S} 6$ cells. A sample of total M. gallisepticum RNA and the 23mer oligonucleotide complementary to the pMGA1.1 gene and depicted in Fig. 7(b) were used for reverse transcription. A single extension product was obtained and calculated to be 79 nucleotides from the first base of the translational start codon. Based on the 'sense' strand sequence of pMGA1.1 this extension product revealed that a ' $G$ ' was the first nucleotide of pMGA1.1 transcription which is 4 bases downstream from the most $5^{\prime}$ of the two predicted promoters identified in a previous publication from this laboratory (Markham et al., 1994). Fig. 7(c) depicts an alignment between sequences of several pMGA genes corresponding to the promoter segment of pMGA1.1. The -10 boxes of these genes are highly conserved whereas their -35 boxes exhibit considerably more variation.

\section{DISCUSSION}

Previous studies from this laboratory suggested on the basis of serological and electrophoretic evidence that three different strains of $M$ gallisepticum, S6, R and F, expressed single, unique variants of pMGA (Markham et al., 1992). A detailed analysis of strain S6 pMGA confirmed that it produced a single major amino-terminal sequence with no evidence of heterogeneity. The results of the amino-terminal sequencing experiments on the pMGA proteins from strains $R$ and $F$ are presented in Fig. 1 and the data compared to the corresponding segments of the pMGA1.1 and pMGA1.2 coding segments. Clearly the pMGA proteins from strains $R$ and $F$ are encoded by different genes; both sequences exhibit higher homology to the pMGA1.2 gene than to pMGA1.1. Importantly, in both $R$ and $F$ strains, as in the S6 strain, a single pMGA gene had been selected for expression from a larger repertoire (Markham et al., 1993). The observation that strain $\mathrm{F}$ may contain an additional polypeptide with minor serological cross-reactivity to pMGA requires further work to interpret. Whereas our earlier work on the pMGA proteins of $F$ strain did not detect this minor serologically cross-reactive species found in this work, we cannot rule out the existence of a minor clonal variant within our $F$ strain stock which might express a pMGA molecule different to that expressed by the predominant cell population. The issue of how pMGA gene selection occurs within different $M$. gallisepticum clones is the subject of what follows.

The Northern transfer analysis of $M$. gallisepticum strain S6 mRNA (Fig. 2) using pMGA-specific probes revealed a 
(a)



(b)

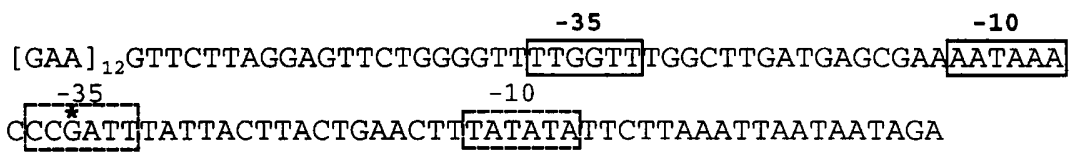

CGTGTTTAACGTAAGTTATTGGCTTAACTTTAAGTG

Extension primer

(c)

pMGA1.1 GGTT TTGGTTTGGCTTGATGAGCGAA

PMGA1.2 GGTTTGGGGCTGGTTTGATCTGCGAAAATTAAGTCGAT

PMGA1.3 GGTTTAGGGOTGGTCTGATCGGCGAA AATAAACGCGAT

pMGA1.4 GGTTTGGGGOTGGTTTGATCGGAGAAAATAAACCCGAT

pMGA1.5 GGTTTTCGTTTGGTCTGATCAGCGAALATAAACGCGAT

\begin{abstract}
Fig. 7. Primer extension analysis of pMGA1.1 transcripts. (a) Lanes: 1, this reaction contained $M$. gallisepticum S6 total RNA, primer and reverse transcriptase; 2, no RNA; 3, no RNA or reverse transcriptase. Lanes 1-3 contained equivalent amounts of primer. The sequencing ladder of the pMGA1.1 sequence (ACGT) is shown as a size standard and is generated with the same oligonucleotide used for the RNA primer extension but using as template pMCC4bHP. An asterisk next to the nucleotide on the left indicates the end-point of the extension. (b) The DNA sequence of the $5^{\prime}$ untranslated region of the PMGA1.1 gene is shown from the GAA repeats to the translational start codon (GTG). The asterisk above the PMGA1.1 sequence indicates the transcription start site; boxed sequences are putative -35 and -10 regions based on E. coli (Hawley \& McClure, 1983) and Mycoplasma (Muto et al., 1992) promoter consensus sequences; the underlined GTG sequence is the translational start codon. (c) DNA alignment of the presumed promoter region of pMGA1.1 and the corresponding regions of four other pMGA genes. Asterisks underneath the alignment indicate nucleotide conservation between all five genes.
\end{abstract}

major mRNA species of approximately $2 \cdot 2 \mathrm{~kb}$. Since the amount of coding potential required for the PMGA genes examined to date is about $1.8-1.9 \mathrm{~kb}$ (Markham et al., 1993), it seems apparent that pMGA genes produce monocistronic mRNA; certainly a polycistronic RNA containing two or more entire pMGA segments is ruled out.

If pMGA expression were governed solely by a transcriptional decision, then PCR amplification of $M$. gallisepticum strain S6 cDNA using primers known to amplify the pMGA1.1 gene should result in the recovery of an amplified product of only this gene. This expectation was not borne out. Under conditions which resulted in the isolation of multiple identical copies of a segment of the TuF sequence, which is a conserved single copy gene (Loechel et al., 1989), several distinct pMGA sequences were found. These particular PCR conditions entailed the use of exo- polymerase. One isolate corresponded exactly to the pMGA1.1 sequence, two isolates differed by single base changes, four by two base changes and the remaining seven sequences differed even more substantially from the pMGA1.1 sequence. One explanation for these findings is to invoke the expression of many pMGA genes at the mRNA level. The analysis of the cloned PCR product of TuF mRNA revealed no sequence variation at all between numerous independent $\mathrm{TuF}$ clones even though exo ${ }^{-}$ DNA polymerase had been used in the PCR. Notwithstanding the sequence homogeneity of the PCR product obtained by RT-PCR with the TuF system, it became apparent that the variant pMGA1.1 and pMGA1.2 sequences obtained using conserved pMGA primers were most likely caused by PCR errors rather than by the existence of a family of pMGA1.1 or pMGA1.2 genes. 
Specifically, Southern blot data were most consistent with the existence of only two pMGA genes capable of binding a probe specific for pMGA1.2. They are known to be pMGA1.1 and pMGA1.2. In addition, use of a DNA polymerase with proofreading activity to conduct PCR reactions greatly reduced the number of sequence disparities between the authentic pMGA1.1 and pMGA1.2 sequences and their derived PCR products (Fig. 5). It therefore seemed simplest to assume that the sequences grouped under authentic pMGA1.1 in Fig. 5 were all products of pMGA1.1 mRNA molecules, those most similar to pMGA1.2 exclusively from pMGA1.2 mRNA, etc. Even so, the expression of at least four genes of the pMGA family at the mRNA level was not entirely anticipated. The abundance of the mRNA for pMGA1.1 relative to that of three other $\mathrm{pMGA}$ genes leaves little doubt that the transcriptional activity of this gene far exceeds that of other related genes within the S6 cells used. The primary control mechanism in pMGA gene selection must therefore be transcriptional. The detection by both RT-PCR and Northern blot analysis of PMGA1.2, 1.4 and ' 1.8 ' transcripts in $M$. gallisepticum S6 cells leaves no doubt that these pMGA genes are simultaneously transcribed along with pMGA1.1 albeit at considerably lower levels. No evidence of the translation of pMGA genes other than pMGA1.1 in S6 cells has yet emerged based on a range of polypeptide and amino acid sequencing studies, although these techniques may not have been sensitive enough to detect any minor pMGA variants. Whether some post-transcriptional mechanism reduces the stability of mRNA or polypeptide products derived from pMGA genes other than pMGA1.1 is not known. Alternatively, even if such pMGA variants were expressed at the protein level specific serological reagents which bound these variants uniquely would be required for their detection.

The data of Fig. 7 clarify the location of the transcriptional start nucleotide of the pMGA1.1 gene and define the likely promoter motif for this gene. Notably the -10 and -35 boxes indicated in Fig. 7(c) correspond closely to one of the two alternative putative promoter motifs predicted in a previous publication from this laboratory (Markham et al., 1994). Whereas exactly the same -10 box occurs in four pMGA genes, including pMGA1.1, the -35 box of pMGA1.1 differs from that of all the other listed pMGA genes. Whether its unique -35 box is the salient factor which endows the pMGA1.1 gene with greatly enhanced transcriptional activity in this strain of $M$. gallisepticum remains to be determined.

Recent work in this laboratory has demonstrated that an epitope-specific antibody directed to the pMGA1.1 protein results in the transcriptional silencing of its gene. The transcriptional inhibition was alleviated when this antibody was removed and pMGA1.1 expression was restored (P. F. Markham, M. D. Glew \& I. D. Walker, unpublished data). These results imply a reversible switch between two alternative transcriptional states. Such transcriptional switches have already been described in other bacterial systems and in some cases involve specific
DNA inversion events (Van De Putte \& Goosen, 1992), in others DNA methylation events (van der Woude et al., 1992). Whether either category of events apply to the transcriptional control of pMGA gene expression in $M$. gallisepticum remains to be determined.

\section{ACKNOWLEDGEMENTS}

We thank Mr Mark Walsh for his assistance in the preparation of the digital photographic figures and to the Ludwig Institute For Cancer Research (Melbourne) for the use of their phosphorimager. This work was supported by Australian Research Council grants to I. D. Walker and G. F. Browning.

\section{REFERENCES}

Chomczynski, P. \& Sacchi, N. (1987). Single-step method of RNA isolation by acid guanidinium thiocyanate-phenol-chloroform extraction. Anal Biocbem 162, 156-159.

Church, G. M. \& Gilbert, W. (1984). Genomic sequencing. Proc Natl Acad Sci USA 81, 1991-1995.

Del Sal, G., Manfidetti, G. \& Schneider, C. (1988). A one-tube plasmid DNA mini-preparation suitable for sequencing. Nucleic Acids Res 16, 9878.

Frey, M. L., Hanson, R. P. \& Anderson, D. P. (1968). A medium for the isolation of avian mycoplasmas. Am J Vet Res 29, 2163-2171.

Hawley, D. K. \& McClure, W. R. (1983). Compilation and analysis of Eschericbia coli promoter DNA sequences. Nucleic Acids Res 11, 2237-2255.

Higgins, D. G., Bleasby, A. J. \& Fuchs, R. (1992). Clustal v: improved software for multiple sequence alignment. $C A B I O S \mathbf{8}$, 189-191.

Higgins, P. A. \& Whithear, K. G. (1986). Detection and differentiation of Mycoplasma gallisepticum and Mycoplasma synoviae antibodies in chicken serum using ELISA. Avian Dis 30, 160-168.

Jordan, F. T. W. (1979). Avian mycoplasmas. In The Mycoplasmas, pp. 1-49. Edited by J. G. Tully \& R. F. Whitcomb. New York: Academic Press.

Laemmli, U. K. (1970). Cleavage of structural proteins during the assembly of the head of bacteriophage T4. Nature 227, 680-685.

Loechel, S., Inamine, J. M. \& Hu, P. (1989). Nucleotide sequence of the tuf gene from Mycoplasma gallisepticum. Nucleic Acids Res 17, 10126.

Markham, P. F., Glew, M. D., Brandon, M. R., Walker, I. D. \& Whithear, K. G. (1992). Characterization of a Major Hemagglutinin Protein from Mycoplasma gallisepticum. Infect Immun 60, 3885-3889.

Markham, P. F., Glew, M. D., Whithear, K. G. \& Walker, I. D. (1993). Molecular cloning of a member of the gene family that encodes pMGA, a hemagglutinin of Mycoplasma gallisepticum. Infect Immun 61, 903-909.

Markham, P. F., Glew, M. D., Sykes, J. E., Bowden, T. R., Pollocks, T. D., Browning, G. F., Whithear, K. G. \& Walker, I. D. (1994). The organisation of the multigene family which encodes the major cell surface protein, pMGA, of Mycoplasma gallisepticum. FEBS Lett 325, 347-352.

Matsudaira, P. (1987). Sequence from picomole quantities of proteins electroblotted onto polyvinylidene difluoride membranes. J Biol Chem 262, 10035-10038. 
Muto, A., Andochi, Y., Yamao, F., Tanaka, R. \& Osawa, S. (1992). Transcription and translation. In Mycoplasmas: Molecular Biology and Pathogenesis, pp. 331-347. Edited by J. Maniloff, R. N. McElhaney, L. R. Finch \& J. B. Baseman. Washington, DC: American Society for Microbiology.

Pedersen, S., Bloch, P. L., Reeh, S. \& Neidhardt, F. C. (1978). Patterns of protein synthesis in E. coli: a catalog of the amount of 140 individual proteins at different growth rates. Cell 14, 179-190.

Sambrook, J., Fritsch, E. F. \& Maniatis, T. (1989). Molecular Cloning: A Laboratory Manual, 2nd edn. Cold Spring Harbor, NY: Cold Spring Harbor Laboratory.

Simecka, J. W., Davis, J. K., Davidson, M. K., Ross, S. E., Stadtlander, C. T. K.-H. \& Cassell, G. H. (1992). Mycoplasma diseases of animals. In Mycoplasmas: Molecular Biology and Pathogenesis, pp.
391-415. Edited by J. Maniloff, R. N. McElhaney, L. R. Finch \& J. B. Baseman. Washington, D.C.: ASM.

Sylvers, L. A. \& Beresten, S. (1993). Loss of resolution in gel electrophoresis of RNA : a problem associated with the presence of formaldehyde gradients. Biotech 14, 380-381.

Van De Putte, P. \& Goosen, N. (1992). DNA inversions in phages and bacteria. Trends Genet 8, 457-462.

van der Woude, M. W., Braaten, B. A. \& Low, D. A. (1992). Evidence for global regulatory control of pilus expression in Escherichia coli by Lrp and DNA methylation: model building based on analysis of pap. Mol Microbiol 6, 2429-2435.

Received 27 March 1995; revised 16 June 1995; accepted 12 July 1995. 